\title{
Research on the Practical Effect of College Art Appreciation Course Based on SPOC
}

\author{
Yang Yu, Qinqin Song \\ Nanjing University of Posts and Telecommunications, Nanjing, Jiangsu, China
}

\begin{abstract}
College art appreciation courses play an important role in cultivating students' artistic accomplishments and comprehensive development. However, as far as the traditional teaching at colleges is concerned, there exist some problems. For example, the students are absent-minded about the teachers' intentions. The lack of communication between teachers and students results in the latter's low enthusiasm for learning and the teaching effect is not significant. Based on the development trend of online learning and the SPOC teaching model in the teaching practice of college art appreciation courses, this paper preliminarily constructs the teaching mode and carries out the teaching practice for one semester as well as combines the teaching practice and then from the three dimensions of students, teachers, and the environment analyzes the key factors that influence teaching practice. At the same time, the paper explores the ways to promote students' enthusiasm and initiative from the aspects of learning time, content, interaction, evaluation, etc. It also corrects and perfects the teaching mode of college art appreciation course based on SPOC, aiming to provide reference for promoting students' comprehensive development and improvement in teaching effects.
\end{abstract}

Keywords: SPOC, art appreciation courses, artistic accomplishments, effect

\section{Introduction}

The course of college art appreciation is an indispensable part of public art education while the public art education is an important approach to implementing aesthetic education in domestic colleges. With the advent of big data and the changes of national strategy, the demand for comprehensive talents is becoming increasingly urgent under the more obvious integration of technology, culture, and commerce. However, the long-term ignorance of aesthetic education in the domestic higher education has hindered their cultivation of comprehensive talents and comprehensive quality. Therefore, it becomes particularly important to build the college public art education system in line with the trend of the times.

At present, most of the researches on the art appreciation courses in colleges focus on the theoretical analysis and empirical countermeasures to the status quo and existing problems, such as the lack of attention and complete curriculum system, single teaching material form, limited curriculum resources (Yan, 2018), especially the backward teaching means, lack of enthusiasm among students, single teacher-student interactive mode (Xiang, 2016), isolated teaching content, lack of students' "pre-education" (Zhang, 2018), "one size fits

\footnotetext{
Yang Yu, master's degree, Associate Professor, College of Media and Arts, Nanjing University of Posts and Telecommunications, Nanjing, Jiangsu, China.

Qinqin Song, master's degree, College of Media and Arts, Nanjing University of Posts and Telecommunications, Nanjing, Jiangsu, China.
} 
all" examination method, etc. (Wu, 2008); accordingly, the corresponding countermeasures were put forward, including breaking resource monopoly with "Internet + education", respecting students' diversified and individualized learning needs, carrying out multi-channel teaching activities, offering students with both study and psychological care (Xiang, 2016), interdisciplinary "collaborative teaching model" (Zhang, 2018), strengthening the building of related courses, teachers and teaching materials, improving assessment methods, etc. (Wu, 2008). Nevertheless, the essence of the problem is still ignored: Firstly, the importance of aesthetic education is undeniable, and the status of college public art education in the cultivation of students' comprehensive quality is far more important than the status of decades ago. Secondly, art appreciation course is the big premise for implementing aesthetic education in colleges, that is to say, only with beauty discovering and understanding ability, can they better master and apply beauty, and the exploration of appropriate teaching mode is an important way to prolong its effect.

With the emergence and rapid development of MOOC (Massive Open Online Course) in 2012, there is an educational reform worldwide, which dramatically impacts on the traditional education model. However, lots of disadvantages are exposed gradually, such as high registration rate, low completion rate, adverse to the sustainable development of the curriculum, less direct teacher-student contact, adverse to in-depth learning, and so on. Taking the characteristics of college art appreciation courses in consideration and combining with the relevant teaching practice at home and abroad, this study takes the opportunity, trying to apply the SPOC (Small Private Online Course) to the course for observing and summarizing the teaching effect. Basically, SPOC is the inheritance, perfection, and transcendence of MOOC, which has realized the reconstruction of teaching process and the innovation of teaching mode (He \& Cao, 2015). Based on MOOC mode, SPOC teaching model is a kind of flipping classroom model. Firstly, students would study independently on the MOOC platform, which provides high quality teaching resources. Secondly, they would conduct face-to-face interaction and collaborative learning in the physical classroom with teachers and students, in this way, the existing MOOC course is perfectly combined with the traditional classroom teaching method. Besides, by giving full play to their respective advantages, the mixed online \& offline teaching mode is realized, thus improving the teaching efficiency (Xu, Wang, \& Zhang, 2016).

\section{The Preliminary Construction of Teaching Model (Construction. Contrast)}

Based on the course of the "Falling in Love with Advertising-Advertising Art Appreciation" SPOC independently developed and designed by MOOC, this study applies the SPOC teaching model to the teaching of this course, discusses the practical teaching mode based on SPOC, providing reference for the college art appreciation course reform, the promotion of the students' artistic literacy as well as students' all-round development.

\section{Analysis of Curriculum Characteristics}

Curriculum characteristics are the primary factors to be considered in the application of SPOC teaching mode. The correct analysis of the characteristics of "Falling in Love with Advertising-Advertising Art Appreciation" is the basis for its SPOC teaching model construction.

Based on the different teaching objectives, the college art education can be divided into two categories, which are professional art education and non-professional art education (college public art education). Generally, the college public art education is mainly aimed at non-professional students (that is, non-art major 
students), which is an education method for improving their artistic accomplishment, cultivating their aesthetic appreciation, discovering their brain potential and creativity, improving their personality through the study, appreciation and practice of art, music, dance, etc. Basically, professional art education emphasizes the exploration and understanding during art practice (Zhang, 2018) while the public art education features certain difference in teaching methods and professional art education. Compared with the specialized, refined, and in-depth features of professional art education, the college public art education pays more attention to the breadth of the art category, the interest of the content, and the interactivity of the process, hoping to improve students' artistic literacy through the understanding and appreciation of certain art categories in a relatively short period of time (Yan, 2018).

\section{Development Trend of SPOC-Based Teaching Mode}

At present, the application of SPOC courses includes online learning mode, mixed teaching mode, flipping classroom mode, and so on (Zeng et al., 2015). The SPOC-based teaching model has also achieved remarkable results. San Jose State University in California implemented SPOC with the "principles of circuits" course by Professor Arnadt Agarwal, who is authorized by the Massachusetts Institute of Technology, with the passing rate ("C" or higher) increasing from 59\% to 91\% (Xu, Jia, Fox, \& Patterson, 2014). Xue Yun and others constructed the "Four Three" teaching model of basic computer courses in flipped classroom based on SPOC, which received remarkable evaluation with regard to the satisfaction, recognition, and participation among students, besides, it also has certain guidance and reference value for the teaching reform of computer basic courses (Xue \& Zheng, 2016). Ding Yonggang and others put forward the flipping classroom 2.0 teaching model based on SPOC, emphasizing the personality and dominant position of students for promoting their in-depth learning (Ding, Jin, X. Zhang, \& Y. Q. Zhang, 2017).

It can be seen from above that, the SOPC teaching model attaches great importance to the students' principal position, which is conducive to the improvement of their autonomous learning ability, as well as practice and exploration ability.

\section{Preliminary Construction of the Model}

The SPOC-based teaching mode construction of "Falling in Love with Advertising-Advertising Art Appreciation" should not only fully display the comprehensive characteristics of art appreciation courses, but should also be student-centered so as to promote students' autonomous learning and study enthusiasm. The preliminary construction of SPOC teaching model is shown in Figure 1: 


\section{Online learning platform}

\section{Offline classroom}

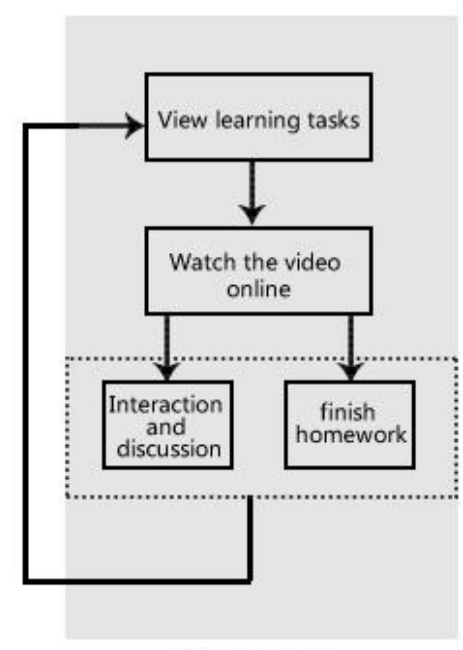

Before class: Autonomous learning

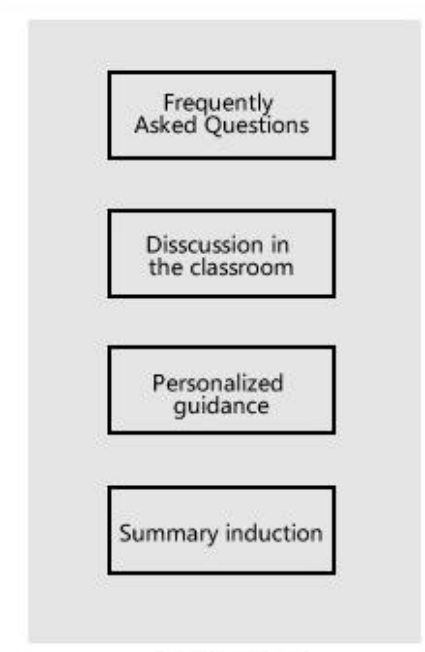

In the class: Knowledge Internalization

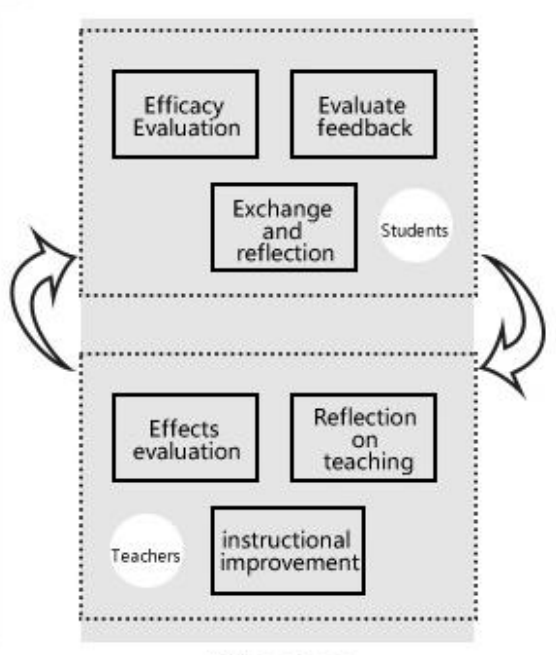

After class:

Development of new knowledge

Figure 1. The SPOC-based teaching model of "Falling in Love with Advertising-Advertising Art Appreciation".

\section{The Research of the Curriculum Practice Effect}

For understanding the students' attitude and satisfaction to this course's SPOC teaching model, the teaching effect questionnaire was designed based on the flipping classroom satisfaction model. A total of 50 students filled out the questionnaire, with 49 copies of valid questionnaires and $98 \%$ effective rate. All the collected data were statistically analyzed by SPSS20.0 software. The results are as follows:

\section{Students' Attitude Towards SPOC Teaching Mode}

According to the analysis of the survey data, for the SPOC teaching mode, $61.2 \%(\mathrm{~N}=30)$ students "love it a lot" while $36.7 \%(\mathrm{~N}=18)$ "like" it. At the same time, 93.9\%, 93.9\%, 98\%, 100\%, 89.8\%, and 95.9\% of the students "incredibly agree" or "agree" with the SPOC teaching model's function on autonomous learning ability enhancement, learning efficiency improvement, reasonable arrangement of study time and adjustment of learning progress, full use of spare time and fragmented time, enhancement of communication and cooperation skills, and training and development of creative thinking (as shown in Table 1). In addition, $46.9 \%(\mathrm{~N}=23$ ) and $46.9 \%(\mathrm{~N}=23)$ of them would "definitely choose it again" or "will choose it again" out of interest and effect of the teaching model and course. The $46.9 \%(\mathrm{~N}=23)$ and $53.1 \%(\mathrm{~N}=26)$ of them "so expected" or "expected" other subjects to apply the SPOC teaching model; $57.1 \%(\mathrm{~N}=28)$ and $42.9 \%(\mathrm{~N}=21)$ of the students were "extraordinarily willing" or "willing" to recommend the course and the SPOC teaching model to their classmates. As can be seen from the above data, most of the students hold positive attitude for the course and the SPOC teaching model. 
Table 1

Students' Attitude Towards SPOC Teaching Model

\begin{tabular}{llll}
\hline & $\begin{array}{l}\text { Agree } \\
\text { (No./Proportion) }\end{array}$ & $\begin{array}{l}\text { Totally agree } \\
\text { (No./Proportion) }\end{array}$ & $\begin{array}{l}\text { Total } \\
\text { (No./Proportion) }\end{array}$ \\
\hline It is conducive to the improvement of autonomous learning ability & $26 / 56.5 \%$ & $20 / 43.5 \%$ & $46 / 93.9 \%$ \\
It is conducive to the improvement of learning efficiency & $27 / 58.7 \%$ & $19 / 41.3 \%$ & $46 / 93.9 \%$ \\
$\begin{array}{l}\text { It is conducive to reasonably arrange the learning time and adjust } \\
\text { the learning schedule }\end{array}$ & $28 / 58.3 \%$ & $20 / 41.7 \%$ & $48 / 98.0 \%$ \\
$\begin{array}{l}\text { It is conducive to make full use of spare time and fragmented time } \\
\text { It is conducive to the improvement of communication and }\end{array}$ & $31 / 63.3 \%$ & $18 / 36.7 \%$ & $49 / 100 \%$ \\
$\begin{array}{l}\text { cooperation ability } \\
\text { It is conducive to the exercise and development of creative thinking }\end{array}$ & $26 / 55.3 \%$ & $20 / 45.5 \%$ & $44 / 89.8 \%$ \\
\hline
\end{tabular}

\section{Students Satisfaction}

Seven dimensions of students satisfaction were investigated in this study, which are environment, curriculum, platform, evaluation, interaction, teachers, and self-improvement, respectively. The Cronbach's $\alpha$ value of each dimension exceeded 0.8, and the overall one was 0.974 (see Table 2). For the construction validity, the KMO value of the scale was 0.781 while the Bartlett's sphericity tested Sig value was 0.000, which was less than the significant level 0.05 , indicating that the data were suitable for factor analysis.

Table 2

Reliability Analysis of Student Satisfaction in All Dimensions

\begin{tabular}{llll}
\hline Dimension & Specific secondary dimension & Topics No. & Cronbach's $\alpha$ \\
\hline Environment & Time, equipment, place & 4 & 0.886 \\
Course & Content design, flexibility, practicality, review and media presentation & 5 & 0.876 \\
Platform & Functional design, usability & 2 & 0.881 \\
Evaluation & Diversification evaluation & 2 & 0.813 \\
Interaction & Student-student, teacher-teacher & 4 & 0.896 \\
Teacher & Curriculum mastery, knowledge reserve, attitude, teaching ability & 4 & 0.928 \\
Self-improvement & Participation, perceived usefulness, expected confirmation, enthusiasm & 4 & 0.889 \\
\hline
\end{tabular}

According to the results, $65.3 \%(\mathrm{~N}=32)$ of the students were "very satisfied" with the teaching while $34.7 \%$ $(\mathrm{N}=17)$ of them felt "satisfied". Among them, the satisfaction degree for the "teacher" and "curriculum" dimension reached 4.61, which are the highest while the dimension of "interaction" is 4.48, which is the lowest (see Table 3 ).

Table 3

Analysis of Student Satisfaction

\begin{tabular}{lll}
\hline Dimension & Average value & Standard deviation \\
\hline Environment & 4.54 & 0.477 \\
Course & 4.61 & 0.428 \\
Platform & 4.55 & 0.513 \\
Evaluation & 4.56 & 0.452 \\
Interaction & 4.48 & 0.496 \\
Teacher & 4.61 & 0.448 \\
Self-improvement & 4.55 & 0.442 \\
\hline
\end{tabular}

The secondary indicators with higher student satisfaction are "curriculum mastery" (4.57), "knowledge reserve" (4.63), "attitude" (4.63), "teaching ability" (4.57) in the "teacher" dimension, as well as the "content 
design" (4.69), "flexibility" (4.61), "practicability" (4.53), "examination" (4.61), "media presentation" (4.59), etc. in the "course" dimension. In the later stage interview, most students claimed that they agreed with choosing the learning content and assessment methods according to the interest within a certain range, besides, in their opinion, the combination of pre-class self-study and class guidance would make them confident of their learning efficiency and ability improvement. The secondary index with lower student satisfaction is "student interaction" in the dimension of "interaction". In the open questions of the questionnaire, based on their learning experience, the students listed the shortcomings or improvements in the course, most of whom mentioned that "It's necessary to enhance interaction between students", "I think the course is OK, however lack of interaction between students", "I hope students can communicate with each other actively", which accordingly, reflects the existing problems and status quo of most current network teaching.

\section{Conclusions}

Through the one-semester course practice, it did not only prove the rationality of the SPOC mode application in art appreciation course, but could also improve the students' autonomous learning ability, learning efficiency, communication and cooperation ability. Besides, it is beneficial for them to reasonably arrange study time and adjust learning progress, make full use of spare time and fragmented time, exercise and develop creative thinking, etc. Moreover, it got further understanding of the ways to promote students' learning enthusiasm and initiative, and revised the SPOC-based teaching mode.

\section{The Revision and Perfection of the Practical Teaching Mode of the SPOC-Based College Art Appreciation Course}

Based on the research and summary of the above action, the revised SPOC-based practical teaching model of "Fall in Love with Advertising-Advertising Art Appreciation" is shown in Figure 2. The revised model highlights the importance of offline communication, clarifies that the task of teaching is to promote students' enthusiasm and initiative in learning, meanwhile, it also highlights the importance of learning evaluation and interactive discussion.

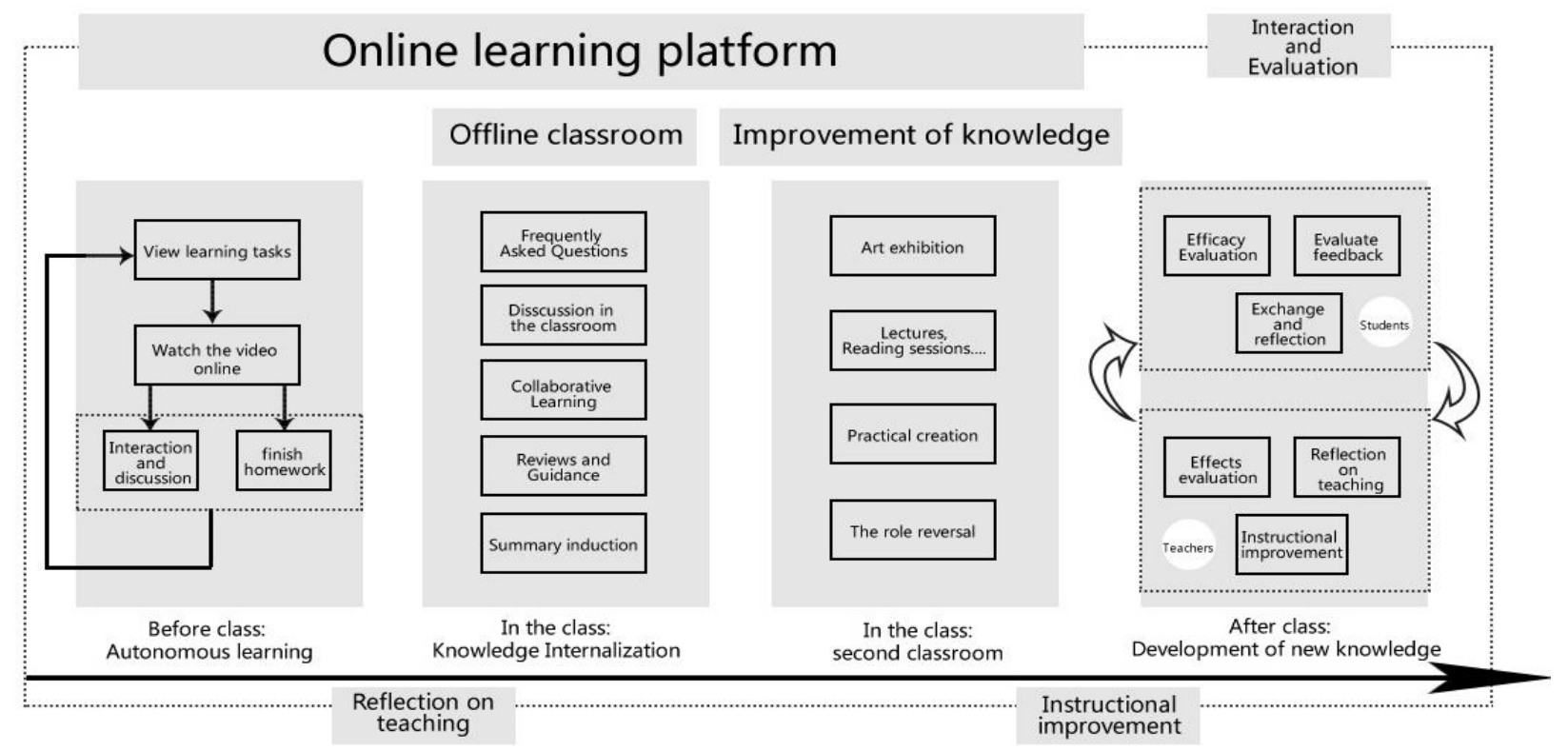

Figure 2. The modified SPOC-based teaching model of "Falling in Love with Advertising-Advertising Art Appreciation". 


\section{The Ways to Promote Students' Enthusiasm and Initiative in Learning}

Currently, the main goal of the introduction of SPOC teaching mode to the domestic college public art education is to promote students' enthusiasm and initiative for learning and make them the master of learning. The following suggestions are put forward combined with the teaching effect of this course and the students' learning feedback:

(1) Refining the learning content. In the questionnaire, some students complained that "With too much course content, I can't decide which are necessary videos, so I have to watch all the videos", "I hope that course videos can be divided in line with country category or advertising type", "I think it's important to add advertising categories, such as animation type", etc. This demands teachers to actively understand the differences between students and their varied interest before conducting the SPOC teaching, integrate the art appreciation courses across disciplines, carry out top-level design by combining and utilizing the college characteristics and resource advantages, thus promoting the structural optimization of the college public courses, carrying out the comprehensive, intersecting, and infiltrating construction.

(2) Enriching the interactive discussion. One of the main shortcomings of online learning is that the teacher-student, and student-student face-to-face interaction decreased. On the contrary, human-computer communication methods such as learning forums and communication groups increased, which are lack of sense of ritual and affinity. Besides, according to the questionnaire, many students mentioned the "lack of interaction between students", "lack of interaction in class", "lack of offline brainstorming". Therefore, teachers can set up second classes based on school resources and students interest besides online learning, such as holding lectures, exhibitions, competitions, reading groups, social practices, and other extracurricular activities. In addition, it is great to add creative practice to the curriculum design of the first class, guide students to solve problems in group, and promote the communication between them and the burst of inspiration.

(3) Diversified evaluation and assessment methods. Compared with the traditional evaluation and assessment mode, that is, "final exam determines everything", the SPOC teaching mode is more humanized with its assessment consisting of the discussion enthusiasm, course completion, self-grade, mutual grade, and examination. However, there are still some students wondered that "It can't be revised after self-assessment and mutual-assessment", "For the final exam, its form changed while the content remained". Therefore, it is necessary to fully realize the diversity and differentiation of assessment and examination methods, prolong the time length of self-assessment and mutual-assessment, increase the type for assessment, and allow students to choose their interested content for assessment. According to the survey, the student assessment type features preference differences. For example, in the creativity and theory assessment, 63.3\% ( $\mathrm{N}=31)$ of the students like creative types while $63.3 \%(\mathrm{~N}=31)$ of them prefer theoretical ones, which requires teachers to provide different choices so as to meet their diversified needs.

\section{References}

Ding, Y. G., Jin, M. T., Zhang, X., \& Zhang, Y. Q. (2017). Design and implementation process of the teaching model of flipped classroom 2.0 based on SPOC. China Educational Technology, 2017(06), 95-101.

He, B., \& Cao, Y. (2015). SPOC: MOOC-based innovation of teaching processes. China Educational Technology, 2015 (3), $22-29$.

Wu, W. B. (2008). Study on the art appreciation course of advertising science. Journal of Henan University of Technology (Social Science Edition), 4(04), 129-131+139.

Xiang, Y. F. (2016). Problems and countermeasures in current college art appreciation courses. Culture and Education Materials, 2016(10), 61-62. 
Xu, W., Jia, Y. Z., Fox, A., \& Patterson, D. (2014). From MOOC to SPOC: Lessons from MOOC at Tsinghua and UC Berkeley. Modern Distance Education Research, 2014(04), 13-22.

Xu, X. F., Wang, Z. Y., \& Zhang, R. (2016). Study on the practice effect of college physics course based on SPOC-A case of physics course in Tongji University. Modern Educational Technology, 2016(03), 87-93.

Xue, Y., \& Zheng, L. (2016). Exploration and reflection of SPOC: Based teaching model in flipped classroom. China Educational Technology, 2016(05), 132-137.

Yan, D. T. (2018). Analysis of the status and problems of public art education in local universities. Art Education, 2018(16), 161-162.

Yan, X. S., Yin, J. M., \& Lin, L. L. (2015). Construction of China's flipping class satisfaction model from the perspective of structural equations. Higher Education Exploration, 2015(05), 65-72.

Zeng, M. X., Li, G. P., Zhou, Q. P., Qin, Z. Y., Xu, H. Z., Zhang, B. L., .. Guo, X. (2015). From MOOC to SPOC: Construction of a deep learning model. China Educational Technology, 2015(11), 28-34+53.

Zhang, Y. W. (2018). The contemporary transformation and value extension of public art education in comprehensive universities. University Teaching, 2018(07), 69-71+76. 